\title{
Chapter 10 \\ Performing Science in Public: Science \\ Communication and Scientific Identity
}

\author{
Sarah R. Davies
}

This chapter asks: what kind of scientific identity work is going on within public communication of science? Or, to put it a different way: how do scientists use science communication to construct identities as scientists and members of scientific communities? These questions take for granted that public communication is, in fact, implicated in scientific identity-building, and that's something I'll return to. But- to jump straight to my conclusions - the chapter will not answer these questions in any tidy way. In line with the conceptual framework presented in the introduction to this volume, I will suggest that categories like 'identity' or 'scientific community' are unstable. Indeed, when we apply them to my data-interviews and participant observation of a large science festival-they blur, become unusable. They will not fit. This in itself is one of my findings.

Why am I confident that science communication ${ }^{1}$ does scientific identity work? There are both historical and contemporary reasons for this. History of science has shown that science and its publics have always been co-produced (Shapin 1990). Early scientists needed reputable (meaning: white, male, upper class) public witnesses to vouch for the trustworthiness of their work (see, e.g. Shapin 1994, 2010). The public performance of experimentation, or at least the possibility of such public performance, was essential to portraying science and scientists as reliably authoritative. Scientific identity since then has trodden a delicate line between being the same as such public audiences-with scientific knowledge framed as

\footnotetext{
${ }^{1}$ Here I am concerned solely with science communication to public audiences, rather than intrascientific communication (which is certainly also involved in identity construction). For more on this distinction see Horst et al. 2016; Palmer and Schibeci 2014; in the rest of this essay, 'science communication' should be understood as referring to public science communication.
}

\section{S. R. Davies $(\bowtie)$}

Department of Science and Technology Studies, University of Vienna, Vienna, Austria

e-mail: sarah.davies@univie.ac.at 
commonsensical, accessible, or mundane-and being exotically different and uniquely authoritative, and therefore worthy of special treatment (Broks 2006; Shapin 1990). For instance, Thomas Gieryn describes the way in which battles around the status of phrenology as (pseudo)scientific were played out in nineteenth century Edinburgh through cultural and political debates over who should be awarded a vacant university chair (Gieryn 1999, p. 115-182). The question of what made for good 'science' - and therefore of who deserved the chair-was not an internal debate; rather, it involved public canvassing, political machinations, and debate of scientists' characters. Nineteenth and twentieth century educational and popularisation activities (from Mechanics Institutes to educational pamphlets or museums) similarly answered a number of boundary work and identity-building purposes, from defining science's 'others' to reinforcing particular social orders or constructing a shared national identity (Bensaude-Vincent 2009; Shapin and Barnes 1977; Topham 2009). Scientists have always used public communication to craft shared understandings of what science is, and what it means to be a scientist.

Scholarship on contemporary science has also emphasised the entanglement of public communication and scientific identity. Felt and Fochler (2012, 2013), for instance, use the notion of 'epistemic living spaces' to describe how scientists' worlds may be shaped by public narratives about science. Epistemic living spaces are 'researchers' individual or collective perceptions and narrative re-constructions of the structures, contexts, rationales, actors and values which mould, guide and delimit their potential actions' (2012, p. 136). They represent what is thinkable and possible in a particular environment, including about one's role and community. These living spaces are flexible and require constant work and adaptation. Felt and Fochler describe how junior scientists, in particular, are affected by the 'excellence narratives' that circulate in public_-stories within which science is clearly linear, progresses towards applications, and where one's career will ultimately lead to a stable academic position (2013). Held up against such stories, 'the individual lives of young scientists are deficient nearly by default' (ibid., p. 10). In a similar vein, Baudouin Jurdant has argued that popular science writing is in fact more for scientists than for publics. It can be understood as the 'autobiography' of science and thereby as a means of 'making real' its discourses and theories (1993). Popularisation, he writes, 'seems to have an epistemological role to play within science itself' (ibid., p. 371).

The shaping of epistemic living spaces through public communication is not stable. Maja Horst has shown that scientists may take on different roles within science communication, relating to their representation of different kinds of scientific collectives (2013). They might perform as an 'expert', representing their field of expertise, as a 'research manager', representing their organisation, or as a 'guardian of science', representing the institution of science as a whole. The part they play in public communication therefore relates to different scientific roles they may choose to take on (as a manager, for instance, or as a member of a particular discipline); importantly, individual scientists do not exclusively inhabit particular roles but may take one or the other depending on the immediate context. At a micro level, we can thus view identity as hybrid, flexible, and subject to shifting structural and contextual 
needs (Lam 2010). One such need may be the relation between individual and group identity. Are scientists speaking for themselves, and thereby performing an individual identity, or are they involved in constructing organisational or disciplinary identity? Brosnan and Michael (2014) have shown, for example, that a single group leader may come to represent the possibilities of a whole field of research, along with symbolising their group, while Horst (2013) also argues that scientists' performances of organisations have a particular character and tone. We might understand tensions between university communication departments and communicating scientists as arising from these dynamics. Scientists may see themselves and their public communication as their concern and their activities as reflecting on themselves alone; communication or press departments, however, view the organisation as inevitably implicated in scientists' public representations (Autzen 2014; Davies and Horst 2016).

These accounts demonstrate, in different ways, how scientific identity is co-produced with public communication. In this chapter I am concerned with how this happens in practice, and what we can learn about this process through close empirical examination of an example of science communication. In what follows I unpack findings from a study of a large science festival, Science in the City, held in Copenhagen in June 2014. First, I describe the conceptual framing I am mobilising; second, in a series of three empirical sections, I present a series of vignettes from the Science in the City festival, using these to explore how identity was performed; and third, I draw together my findings to offer some reflections on the wider question of the relation between scientific identity and the practice of public communication.

\subsection{Identity as Performance}

It will be clear from the discussion above that I am working with a generous definition of identity: I see it as relating to role, boundary work (or role differentiation), and community. Most importantly I view identity as processual. It is not something that is fixed or stable, but a performance that may be carried out differently in different contexts. (With regard to the becoming/performing dicotomy described in the introduction to this volume, this analysis is firmly oriented to performance.) This view can be traced back to the work of Erving Goffman and the notion that the self is not something that is expressed or experienced within interaction in any pure or authentic way, but rather is performed (Goffman 1955, 1959). Social interaction, Goffman argues, involves the performance of particular characters. As in the theatre, everyday life requires individuals to convincingly produce a certain version of the self. A 'character' is a 'figure, typically a fine one, whose spirit, strength and other sterling qualities the performance [is] designed to evoke' (1959, p. 244). Understanding social interaction in these terms has a number of implications. One is that performances are contextual: a certain setting (what Goffman calls a region) may require one kind of character, while another calls for one that is very different. We perform our selves in different ways with our lovers and our bosses; 
analytically, those performances can reveal something about what qualities we believe are prized in each context. A further implication is that work is involved in the presentation of the self. Goffman calls the performer a 'harried fabricator of impressions' (p. 244) and writes that to 'be a given kind of person ... [is] to sustain the standards of conduct and appearance that one's social grouping attaches thereto' (p. 81, emphasis in original). Even if the maintenance of these standards feels and appears effortless - and may well be entirely unselfconscious - this should not disguise the fact that performances are not innate but learned and require the management of numerous sociocultural cues. The notion of this effortfulness is developed in particular in the idea of 'face-work' (Goffman 1955; Myers 2003) which emphasises that any encounter is liable to fail-that is, that one or more of those involved may 'lose face' as their self-presentation falters or falls down completely.

Goffman's work has been widely taken up in science studies. His notion of 'front stage' and 'back stage', for instance, has been used to discuss the formal and informal presentation of science (see discussion in Greiffenhagen and Sharrock 2011) and resonates with STS concepts such as the use of empiricist and contingent repertoires (Gilbert and Mulkay 1984) or Latour's two-faced Janus as a representation of science (Latour 1987). Greg Myers and other discourse analysts have used Goffman to examine the dynamics of science-based interactions, for instance by exploring how face can be maintained when discussing risk-based topics (Davies 2011; Myers 2003, 2007). Perhaps the most extended use of the performance metaphor, however, and the one that is most relevant to my discussion, is in Stephen Hilgartner's volume Science on Stage (2000), in which he argues that scientific policy advice can be understood as a kind of public drama. Hilgartner opens up the ways in which science advice - and scientists - are perceived as authoritative and relevant; science advisors, he writes, 'use a variety of techniques to create-or better, to enact - the basis of their authority as experts' (p. 6). Similarly to Goffman, he emphasises that understanding the production of authoritative characters (or any other convincing role) as a performance does not imply cynical or manipulative performers. Scientists are not 'con men', they simply have 'multiple identities' (p. 13):

Performers typically seek to display themselves in ways that make them appear to conform to the "identity norms" befitting a person of their status given the nature of the occasion ... In the world of science advice, one of the central identity norms concerns the objectivity (in the sense of disinterestedness) with which advisory bodies approach their charge. Thus ... advisors work hard to enact objectivity (Hilgartner 2000, p. 14)

Again, this highlights the importance of context-the 'nature of the occasion'. Identities are performed in ways appropriate to the current setting: in science, and science advice, unity and objectivity might be fitting to one front stage context, while controversy and contingency are performed on the back stage. In this sense, scientific identity is always a production-requiring the identification of relevant 'identity norms' - and is always shifting.

How to apply this framework to public communication? Viewing scientific identity as processual and hybridic already starts to muddy the waters of my initial 
question (how do scientists use science communication to construct scientific identities?) by fragmenting 'scientific identity' into many different possibilities. A more relevant question might be which scientific identities are performed in public communication. It also raises the question of what front and back stages might be involved in science communication. Much analysis of scientific communication has assumed that this is a process by which science presents a cleaned-up public face to the world - that it is the front stage to the back stage of scientific uncertainty, debate, and hedging. Rae Goodell, for instance, in her seminal account of 'visible scientists' (1975), sees celebrity scientists as 'representatives of the scientific community as a whole' (p. 203) despite the fact that their views may diverge wildly from the consensus; more recently, Declan Fahy has argued that celebrities such as Stephen Hawkings or Richard Dawkins are less communicators than brands encapsulating particular public narratives about science (2015). But, as Hilgartner has suggested, the distinction between front and back stage is not always clear cut: 'each backstage region is the theater for additional layers of performance' (Hilgartner 2004, p. 447). While some public communication may present the glossy, finished version of front stage science, it seems possible that, at times, back stage identities may leak through or are even deliberately performed.

The rest of this chapter reflects on these dynamics through the example of a large public science festival, Science in the City, which was held in Copenhagen in June 2014 over the course of 6 days. The festival as a whole involved dozens of distinct exhibits, activities, and events-from the opportunity to visit a marine research vessel to a dialogue on IP issues in biohacking and an exhibit, based on veterinary research, featuring live pigs. As such, it-like similar festivals-was a distinctive form of science communication, one that offered particularly rich opportunities for multiple identity performances and for slippage between front and back stages. The variety of formats present, and the nature of a live science event in which performances cannot readily be fixed or rendered static, mean that the festival offers a kind of extreme case of identity work within science communication. While I interviewed the lead organiser of the festival and took fieldnotes from participant observation at the festival site, my research largely focused on six science communication projects in particular, seeking to produce a 'thick description' of their production and reception (Ponterotto 2006). I carried out interviews with the organisers of these and focused my participant observation on their physical instantiations (variously, a photo exhibition, two interactive installations, an art piece, a movement-based workshop, and a public lecture). I also collected public responses to them via questionnaires, though these data will not be discussed here. The chapter will not attempt to present results from this research as a whole. ${ }^{2}$ Rather, I will use a number of key vignettes from the festival to illuminate some of the dynamics through which scientific identity was (or was not) negotiated within it.

\footnotetext{
${ }^{2}$ Further information about the festival, the research, and findings from it can be found in Davies and Horst (2016).
} 


\subsection{Science Communication Is Heterogeneous}

I suggested at the start of the chapter that one finding from this research was of a complexity that overtook the research questions I began with. I was interested in scientific identity, and how it might be mediated within science communication, but my engagement with the festival, from my starting point of identifying project 'organisers' to interview, rapidly began to fracture the categories I had begun with. Contra classical accounts such as Goodell (1975) or guides to science communication such as Bennett and Jennings (2011), which position scientists as the key actors within public communication, Science in the City and its constituent communication projects were highly diverse assemblages. Academic scientists were certainly involved (sometimes as lead 'organisers', though sometimes not), but the projects also enrolled, for example, research administrators, artists, professional science communicators, philosophers, event managers, students (paid and as volunteers), university press officers, a local quarry, businesses, social researchers, freelance designers, international organisations, local government, and organisers' friends and family. Enquiring about scientific identity immediately becomes more complex in such a situation. Is this the only identity being performed? And who exactly is able to perform it?

As a brief example it is worth sketching out the organisation of one project, the Seeing the Unseeable installation/exhibition. Seeing the Unseeable was designed to explain and promote the science behind the European Spallation Source (ESS), a particle accelerator then under construction in Lund, in the nearby Skåne region of Sweden. The project was a collaboration between Region Hovedstadet (Copenhagen's city council), the ESS organisation, MAX IV (another local accelerator), the University of Copenhagen, and the Technical University of Denmark. The final installation involved an 'immersive experience' featuring strobe lights in a tunnel-like space, which led into a larger area containing table-top demonstrations of physics experiments, videos and computer interactives, and a lounge area with free coffee and sandwiches. The conceptual development of the space was contracted out to a local science centre, and it was staffed by volunteer students and scientists from the participating universities. These scientists were the 'face' of the exhibition, and their contact with visitors was key to how the project was experienced. But they played only a minor role in its production and development. Far more important were actors such as Mads, the science centre project manager who led the exhibition concept development and training for the volunteers, and Kell, the Region Hovedstadet manager who was seeking to ensure that the ESS would be a 'growth motor' for the region and who was behind the project's funding. ${ }^{3}$ As the project came to fruition, scientific identities were certainly at stake (not least in the context of Mads' interest in promoting a particular version of science communication and his concerns that the scientist volunteers were not in line with this). But so were other

\footnotetext{
${ }^{3}$ The names of individuals have been changed.
} 
identities and communities, from 'science communicator' to 'public-spirited volunteer'.

The point here is not to outline in detail how these identities were produced. Rather it is to illustrate some of the diversity of the roles and groups that were implicated within these different science communication projects. One of the reasons it becomes difficult to talk about the production of scientific identity within Science in the City, then, is that so many other personal and professional roles, and thereby identities, were also being performed within these public communication activities. As we will also see, at least some of these overlapped with scientific identities.

\subsection{Scientific Identities Are Multiple}

If the organisation of the different science communication projects indicates some of the complexity of pinpointing performances of scientific identity, so too does the consideration of their timelines. The literature I discussed in the first section often looks at scientific identity at the moment of its contact with public audiences, exploring how science is produced as Other to lay witnesses or public groups even as it interacts with them (see Gieryn 1999; Shapin 1990). There is a rich literature that has explored the versions of science and scientists that are represented within science communication (e.g. Chimba and Kitzinger 2010; Jacobi and Schiele 1989; Weingart et al. 2003), and, certainly, physical instantiations of Science in the City projects promoted some images of scientists over others-as accessible, capable, and humorous, for instance, rather than elite or incompetent. Such representations are not surprising in an environment that explicitly aimed to present science in a positive light. But as the history of Seeing the Unseeable indicates, public communication projects have a hinterland of preparation and development within which scientific identities may also be performed (in Mads' training programme for volunteer scientists, for example, and discussions of good communication behaviours therein). In engaging with the projects, it became clear that scientists framed their identities differently at different moments within them and that particular roles or versions of the self came to the fore at different points. Identities and community memberships were multiple and flexible.

I will illustrate this multiplicity with a couple of examples from two Science in the City projects. The first is taken from Ocean of Resources, which was a large format photography exhibition featuring eight images, each with a paragraph of explanatory text underneath (Fig. 10.1). This was a straightforward and unpretentious project, led in its practical aspects by a university research administrator (Nete) and in spirit by a marine scientist (Harro), who had taken the photographs and developed the text. The project was funded by the Norwegian Research Council and was in fact inspired by the Council's call for projects to participate in the festival; Science in the City was, in other words, an opportunity for Nete and Harro to further develop Harro's photography - which had previously featured in smaller scale, local exhibitions-as a means of public engagement. Both were clear that the project was largely about 


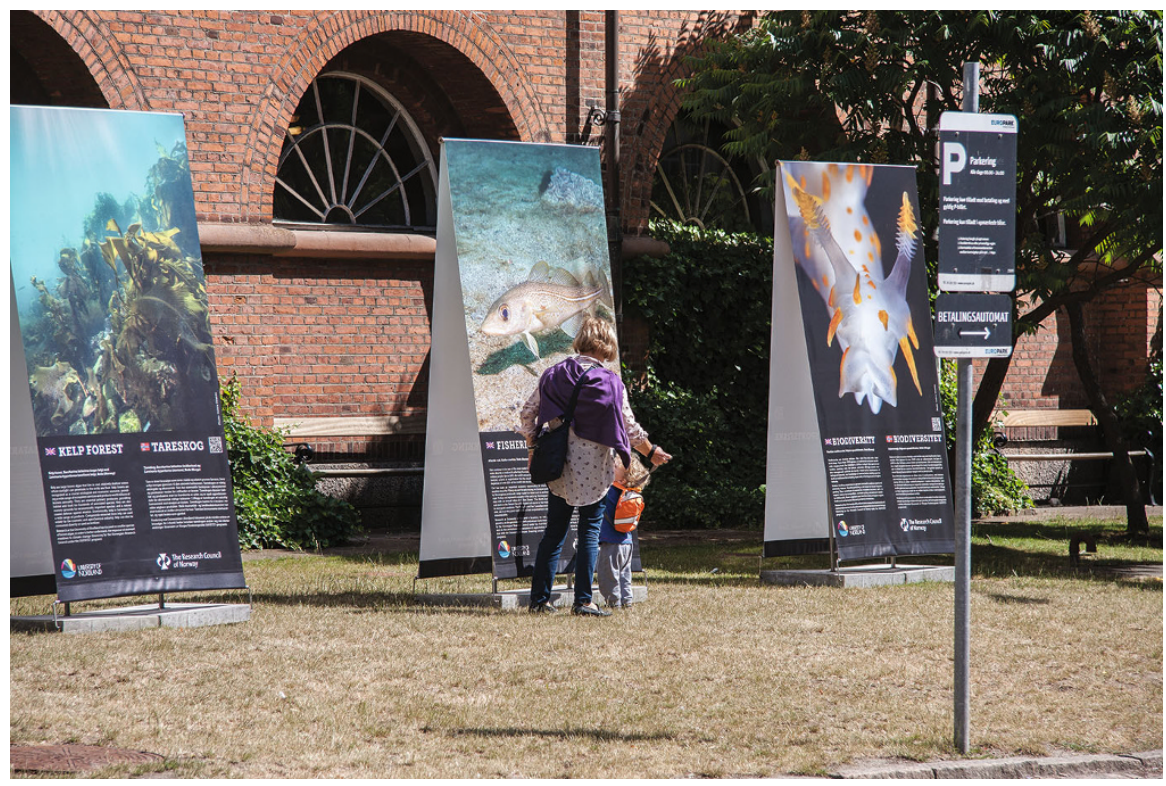

Fig. 10.1 Ocean of resources. (Image by Alexander Dich Jensen (permission granted for use))

branding, gaining visibility, and 'showcasing' university research. This is Harro, for instance, talking about his aims for the project:

...we are really trying to connect each picture to ongoing research activity at the university, and especially the ones that are financed by the research council. So we're trying to use it also as a showcase of what kind of research we are doing ... I think the main goal for me is to really have people to see that, you know, marine resource is not only the fish we eat but it's a lot of other things.

Harro's interests are twofold. He is first concerned with publicising university research: each of the pictures would be explained using examples from his home university and would thereby highlight its activity in this area (and indeed its very existence: Nete and Harro were based at a small university in the far north of Norway and wanted, as Nete said, to 'show off' that it was there and active in research). In this respect, the Norwegian Research Council is not an incidental audience; Ocean of Resources, by seeking out funding from it and by showcasing research that it funds, is able to perform the university in general and Harro in particular as an active and engaged partner of the Council, and thus as a well-established research actor. Along with this performance of organisational identity, Harro also has more didactic aims. The title, Ocean of Resources, refers to marine environments as an important natural resource, and he wants audiences to understand that the oceans are important for 'a lot of other things' besides fishing (for tourism, for example, or preserving biodiversity). The project therefore had some quite traditional science communication goals: Harro sought to promote and publicise 'sound science' in the public domain. 
At the same time, Harro also presented his involvement in the project as part of a quite different identity, one related to leisure and pleasure. One of the first things I asked him was about the relation of the images to his research. Given that he was a marine scientist, I had assumed that the photos were taken during the course of his work. But no, he said, this was 'personal interest. It's not something I use daily in my research'. This was exactly why he and Nete had had to invest energy in-as he says in the quotation above-connecting 'each picture to ongoing research activity at the university'. It similarly emerged that his commitment to the images went far beyond the need for the public to understand that the oceans are an important resource; they were, for him, an affective technology that could convey something of the experience of diving and of encountering underwater life. Though this was difficult for him to articulate, the sense was that images such as those of 'beluga whales who are looking straight at you' were intrinsically powerful and emotional such that 'people [feel] a connection to what they're seeing'. This version of himself had little to do with the dry promotion of research or even with public education. Rather, it was an identity that was about leisure and 'personal interests', but perhaps even more about having a connection to the natural world. Though there was an obvious link to his research activities as a marine scientist, he framed this way of being as rather different - an identity that was more personal than professional and thus a 'back stage' performance.

A second example comes from a public lecture-style event at Science in the City, the Ig Nobel Prize show. This was a local iteration of what has become an international franchise. The Ig Nobel Prizes (for science that 'first makes people laugh, and then makes them think ${ }^{, 4}$ ) are awarded annually at Harvard and receive extensive international press and media coverage; the organiser, Marc Abrahams, also carries out other shows around the world and runs associated activities such as the Annals of Improbable Research. The local organiser, Niklas, was an Ig Nobel laureate and a scientist at a Danish university. The Science in the City festival shows (there were two, identical in format) built on other shows that Niklas had been involved in; as with these previous versions, Abrahams and a number of other Ig Nobel laureates travelled in to present their stories.

Though the Ig Nobels-including the two Science in the City shows-are humorous in tone, and aim to entertain, Niklas was clear that this was a scientific endeavour. All content is 'science based', and the shows involved occasionally 'distinguished' but always 'serious' scientists. Everything presented is 'solid science'. Niklas was also keen to point out the prize's origins at Harvard and the fact that, at the annual prize-giving ceremony, it is actual Nobel winners who give out the awards. Much of the discursive work Niklas did within our interview, then, focused on protecting an identity as a robust, credible scientist against an implied charge of dumbing down or producing mere entertainment. The Ig Nobel Show as authentically scientific and trustworthy was key to his involvement in it and, relatedly, he presented it as a means of educating the public, ensuring their support for basic

\footnotetext{
${ }^{4}$ See http://www.improbable.com/ig/
} 
research (which he saw as under attack) and allowing them to appreciate the wonders of scientific thinking. His aim, he said, was for audiences 'to understand how fun and interesting and beautiful science is and that the most beautiful thing science can do to you is it can make you think. It can enrich your brain'.

The Ig Nobel Show can thus be understood as a means of propagating a particular kind of scientific identity and version of science. It was designed to present and protect science as entertaining and accessible while also being curiosity-driven, reliable, and important. Again, however, there were moments when Niklas took up other identities, in particular when the show was constructed less as a showcase for science and more as an opportunity for particular social identities to come to the fore. There was his conviction, for instance, that the stories the show featured-about different pieces of 'improbable' research-were the narrative equivalents of earworms, such that they would stay with audience members and inevitably spark further reflections and conversations. But it was also clear that his involvement in the show was a means for him to nurture and enjoy a particular community. Having won his Ig Nobel in 2004 - and having greatly enjoyed the experience of participating in the Harvard prize-giving ceremony-Niklas kept in touch with Marc Abrahams and had several times discussed the possibility of participating in a tour. By 2009 or 2010

we started to invite some of the Ig Nobel prizewinners for a small tour in Denmark and we have also been in Sweden some years so we have been there a couple of times before and had shows. And it's always been really nice events. It's almost become like a small tradition, but it's never been as big as [the Science in the City show] is really. This is the biggest event we have been to, so we are very excited about that.

Science in the City was an opportunity not only to publicise the kind of science promoted through Ig Nobel but also to continue the 'small tradition' of a particular group of laureates coming together to perform the show. This was a social event as much as an educative one. Niklas took great pleasure in the sense of community and belonging that the show seemed to involve, continuing to be excited about the stories the laureates told and the chance to work together with them. The Ig Nobel prizes, he said, was a 'movement ... to fight for science', but they also functioned as a way of building community and shared identity for those-like Niklas, Abrahams, and the other laureates involved in the show-who were committed to this aim.

For both Harro (in the Ocean of Resources project) and Niklas (in the Ig Nobel Prize Show), public communication functioned to disseminate particular versions of science and scientific identity. But it also involved other identities, versions of the self connected to leisure, to engagement with nature, or to a particular social group. It is worth noting that it is not easy to pin these different characters (to use Goffman's term) down to front or back stage performances. Harro-the-promoter-of-Norwegianresearch or Niklas-the-serious-scientist might be foregrounded in the final realisation of their two different communication projects, but the other selves that were implicated in those projects were not understood as entirely inappropriate for public view (if they were, it is unlikely they would have been discussed with me in an interview). The Ig Nobel Show was very explicitly a practiced and glossy performance, but I watched Niklas before and after that performance as he chatted and joked with his 
fellow presenters; elements of those interactions - those friendships-found their way into the style of the 'front stage' show. What we might say, then, is that it is not straightforward to distinguish between the front and back stage, at least in this context. It seems possible to respond to multiple 'identity norms', both scientific and from other domains, at the same time.

\subsection{Audiences Are Heterogeneous}

If public communication can involve scientists inhabiting multiple roles at the same time, it seems likely that the same kind of complexity is true of audiences. In this section I look at a final example of how a shared sense of organisational identity was produced within the Science in the City festival, this time by exploring the results of a particular combination of material infrastructure, scientist-communicators, and audiences. Here I am interested in how a specific assemblage of objects and diverse human actors - including the audiences of public communication-allow particular scientific identities to be performed.

My example here moves beyond a single project-the Breaking and Entering interactive installation (Fig. 10.2) - to take in the subsection of the Science in the City site it was situated within. Breaking and Entering was organised by an interdisciplinary group of University of Copenhagen employees and external consultants (researchers, administrators, students, designers), and, as such, it was placed

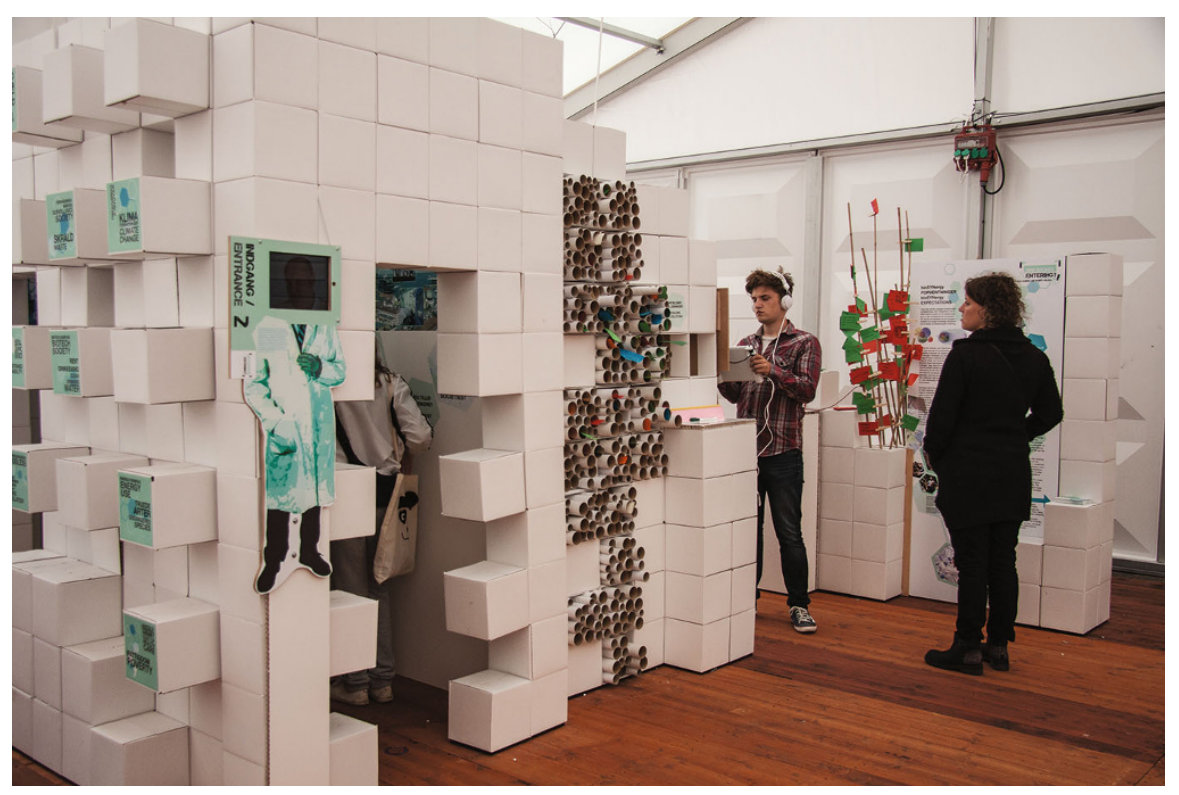

Fig. 10.2 Breaking and entering. (Images by Alexander Dich Jensen (permission granted for use)) 
in what became known colloquially as the 'KU tent' (KU being the abbreviation for Kobenhavns Universitet). ${ }^{5}$ This was a large marquee which housed a number of University of Copenhagen communication projects. In addition to Breaking and Entering, these included a 'teddy bear hospital' run by medical students, a café, an installation developed by the University's International Office describing the experiences of international employees, and a small stage and seating area used for $5 \mathrm{~min}$ 'lightning' research talks and longer chemistry shows. Though the projects had been developed independently - to the extent that there was occasional competition over the use of space or the noise levels - the space had a common design aesthetic and was linked together through the use of wooden pallets as seating throughout (these also appeared in a 'spillover' seating and lounge area outside the marquee). The projects were also linked through the figure of Emilie, the University of Copenhagen project manager who had been tasked with organising the university's presence at Science in the City, and who had liaised with all the projects in advance of the festival and was present throughout.

Six days - the length of the festival-is a long time to spend running a science communication project. Though there were shifts in staffing the KU tent projects at any particular time (the teddy bear hospital, for instance, only ran over the weekend), there was also a core cadre of individuals who were present for the majority of the festival period. These people (as a University of Copenhagen employee, I count myself among them) were there to set up and install their projects before the festival opened; they ate lunch (provided by the university) at around the same time each day, and they shared in the ebbs and flows of visitor numbers and the dynamics of the space. Over the course of the festival the tent became lived in: things broke and were stuck back together; the marquee took on a distinctive smell; we became familiar with each other and with the tent's soundscape. Many of my fieldnotes relate to the KU tent and its dynamics, in part because it contained Breaking and Entering but also because it was simply an easy place for me-a University of Copenhagen staff member-to be. (Unlike some of the other projects I was observing, the space was also protected from the vagaries of the weather.) The community of the tent, both human and non-human, became deeply familiar. By the second half of the festival I could write in my fieldnotes that I had been

reflecting on how mundane and bedded down our activities have become-how everyday the environment is now. At the start it was new and exciting and confusing, but now we have eaten the same lunch in the same place, and sat around the tent, and gauged the dynamics of the space, for several days in a row, and somehow it starts to feel like home.

'We' refers here to myself and other University of Copenhagen staff involved in the festival, in particular those connected to Breaking and Entering but also to the

\footnotetext{
${ }^{5}$ Breaking and Entering was led by my department, and I was one of the researchers involved in its development; on this project, then, my role as not just an observer but also a participant was particularly heightened. Further discussion can be found in chapter three of Davies and Horst (2016). The title refers to the idea of science as an ivory tower which may be infiltrated by society through an act of breaking and entering.
} 
other projects in the tent. Our involvement had become rhythmic and routinised; more than that, it had become collectivised. There was a developing sense of camaraderie as people relaxed with one another and shared the experience of carrying out public communication. Emilie and others held business meetings during quiet moments; volunteer communicators drifted round to look at the other exhibits and chat. The 'KU tent' became an outpost of the university as a whole. Over the course of the festival it turned into a space where, together, we could perform an identity as dedicated university employees concerned with public outreach and collectively construct the university as a socially engaged, relevant organisation. We were concerned not just with personal scientific identity but with ensuring the reputation of a particular scientific organisation.

The work of co-constructing organisational identities was not limited to those involved in running the KU tent projects. Many of the visitors to the space were linked to the university in some way. Senior managers were given tours of the different projects while visiting the festival, project organisers' friends and family came to see what they had been working on, and university colleagues visited projects their departments had been involved in. At moments it was clear that the 'public' audience was largely comprised of those working in research or the academy: a physics-based lightning talk, for instance, that prompted high level technical questions; or another talk for which I sat wedged between my head of department and a senior manager at the faculty. The University of Copenhagen and its members, of course, had an interest in what was being presented at the festival. It was the university, and the nature of those who were part of it, that was being represented through the different $\mathrm{KU}$ tent projects as much as the research that those projects focused on.

We can thus suggest - as the title of this section implies - that the audiences of public communication are heterogeneous. In the case of the KU tent, an important (perhaps even primary) audience was not the lay public but university staff, managers, and others with connections to academic research. ${ }^{6}$ In this sense, Breaking and Entering and the other projects located in the tent were doing what marketing scholarship has called 'auto-communication' (Christensen 1997): performing the identity of the university (and perhaps of institutional science more generally) to existing organisational members. More than this, though, I would argue that we can view the KU tent assemblage as doing significant new identity-building work. The activities, exhibits, social relationships, and atmosphere that developed over the course of Science in the City together helped construct a shared identity as university employees; similarly, they produced the university as a particular kind of research organisation (socially engaged, lively, open). Collegiality, collaboration, and openness were performed, and they thereby in some way became part of the 'identity norms' of University of Copenhagen researchers and staff. In this sense we might not view the KU tent as a 'front stage' performance at all. Rather, the activities it hosted

\footnotetext{
${ }^{6} \mathrm{We}$ also saw this in my discussion of Ocean of Resources. The Norwegian Research Council was both an important partner in and audience for the project.
} 
were doing the back stage work of crafting the public characters we would go on to perform at other sites. The real identity work was done as we fixed broken exhibits and fetched lunch together, with the public performance and communication of science a useful side-effect.

\subsection{Discussion}

I noted at the start of the chapter that this analysis served to destabilise some of the categories of my own research and of the literature on science communication and scientific identity more generally. How to look at scientific identity when it emerges that scientists are only a small part of the assemblage that brings science communication projects into being? Or how to capture what is produced in the interface between 'science' and 'publics' when those publics may themselves take up scientific identities? What my engagement with the Science in the City festival has done is not so much answer my initial question-what kind of scientific identity work is going on within public communication of science? - as fracture it into many different possibilities. Science communication is used by scientists for many different identity-building purposes, in many different ways. It further relates to different kinds of communities: as the guest editors write in their introduction, "entanglements between collectivity and identity are clearly visible, albeit not trivial or tangible in most respects" (p. 30). It thus appears impossible to be definitive- to say, for instance, that public communication is always about boundary work and the protection of distinctive scientific identities, or that 'objectivity' is a stable identity norm (cf. Hilgartner 2000). 'Science communication', to use a single term to represent what appears to be a highly heterogeneous activity, may involve the performance of characters from 'science communicator' to 'nature lover' or 'representative of the University of Copenhagen' rather than, or as well as, that of 'scientist'. In addition, all such characters offer scope for interpretation. The role of scientist is not highly scripted: one might play it as an addendum to a leisure identity, as Harro did, or, as Niklas did, as a social character, part of the production of enjoyable community.

My discussion has similarly muddied the waters of notions of front and back stage within identity construction. ${ }^{7}$ It is not always clear where public performances begin and the back stage work of preparing them ends: the KU tent, for example, might be construed as being only secondarily for a public audience while primarily functioning for internal organisation-building; and even cleaned-up, glossy presentations of science such as the Ig Nobel Prize show may involve back stage-style moments of relaxation. This again encourages us to constantly interrogate the work

\footnotetext{
${ }^{7} \mathrm{I}$ am by no means the first person to problematise a clear distinction between front stage and back stage performances. Most recently, social media has been viewed as one way in which such distinctions are systematically breaking down (Lee 2006).
} 
that is going on in public representations of science. Celebrity scientists may symbolise coherent scientific 'brands' (Fahy 2015), and increasingly public presentations may depict increasing certainty (Greiffenhagen and Sharrock 2011), but, again, this may not always be the case. We cannot take the nature of science, as constructed in public, for granted.

An understanding of science communication as highly complex, and as capable of supporting multiple and flexible identity performances, is thus a key outcome of this analysis. Indeed, I believe that exploring these complexities and contingencies is a productive way forward for studying science communication generally and for understanding the work that such communication does to science and scientists (Davies and Horst 2016). Performances are contingent, identity is shifting, and any instance of public communication is under-determined, offering scope for different kinds of work on the self. In the midst of such complexity, is it possible to say something about the patterning of identity work or the ways in which performances might settle into familiar and repeated repertoires? Certainly, these data do not reveal many hints as to what such patterns and repertoires might involve. As I have argued, diversity is the most striking point. In closing we might look instead to the kinds of notions and resources that could help identify moments of stability - ways in which identity-formation becomes more settled or routinised-in future research. One such resource might be to explore what is clearly taboo or unsayable within science communication. I have noted, for instance, that Science in the City representations of science and scientists tended to portray them as accessible, humorous, and in a positive light; future research might thus interrogate how it is not possible to portray science in public settings (as boring, perhaps, or insignificant).

A further tool for conceptualising the space between actants' agency and the settled patterns through which we experience the world is the concept of "narrative infrastructure' (Felt 2017). Narrative infrastructure forms an 'ambient discursive environment' (ibid., p. 56): it is the web of stories and taken-for-granted ideas and arguments that crystallise around a particular issue. Importantly, though, such infrastructure is dynamic. It is 'temporally stabilised' and therefore transient, and it contains 'actors who create, adapt, multiply, support and entangle ... dominant narratives' (ibid.). Narrative infrastructure, as a concept, could provide one way of looking for wider patterns in the public performance of scientific identity. Which narratives and assumptions frame events such as Science in the City and make particular kinds of performances more likely than others? We might, from the STS literature, start to suggest some possibilities, hinted at by the following terms: public understanding of science, promotion of basic research, democracy, deficit and dialogue, innovation (Davies and Horst 2016; Irwin 2006). But these can only be tentative. One key direction for future research should therefore be further exploration of the framing narratives of science communication. Such work will help articulate the relation between situated performances of scientific identity and the narrative infrastructures that make them possible. 


\section{References}

Autzen, C. 2014. Press releases-The new trend in science communication. Journal of Science Communication 13 (3): 1-8.

Bennett, D.J., and R.C. Jennings. 2011. Successful science communication: Telling it like it is. Cambridge: Cambridge University Press.

Bensaude-Vincent, B. 2009. A Historical Perspective on Science and Its "Others". Isis 100 (2): 359-68. https://doi.org/10.1086/599547.

Broks, P. 2006. Understanding popular science. Maidenhead: McGraw-Hill Education (UK).

Brosnan, C., and M. Michael. 2014. Enacting the 'neuro' in practice: Translational research, adhesion and the promise of porosity. Social Studies of Science 44 (5): 680-700.

Chimba, M., and J. Kitzinger. 2010. Bimbo or boffin? Women in science: An analysis of media representations and how female scientists negotiate cultural contradictions. Public Understanding of Science 19 (5): 609-624.

Christensen, L.T. 1997. Marketing as auto-communication. Consumption Markets \& Culture 1 (3): 197-227.

Davies, S.R. 2011. How we talk when we talk about nano: The future in laypeople's talk. Futures 43 (3): 317-326.

Davies, S., and M. Horst. 2016. Science communication: Culture, identity and citizenship. New York: Palgrave Macmillan.

Fahy, D. 2015. The new celebrity scientists: Out of the lab and into the limelight. Lanham: Rowman \& Littlefield.

Felt, U. 2017. 'Response-able practices' or 'new bureaucracies of virtue': The challenges of making RRI work in academic environments. In Responsible innovation 3: A European agenda? ed. L. Asveld, M. van Dam-Mieras, T. Swierstra, et al., 49-68. Cham: Springer.

Felt, U., and M. Fochler. 2012. Re-ordering epistemic living spaces: On the tacit governance effects of the public communication of science. In The sciences' media connection: Public communication and its repercussions, ed. S. Rödder, M. Franzen, and P. Weingart, 133-154. Dordrecht: Springer.

-2013. What science stories do: Rethinking the multiple consequences of intensified science communication. In Science communication today: International perspectives, issues and strategies, ed. P. Baranger and B. Schiele, 75-90. Paris: CNRS Editions.

Gieryn, T.F. 1999. Cultural boundaries of science: Credibility on the line. Chicago: University of Chicago Press.

Gilbert, N., and M. Mulkay. 1984. Opening pandora's box: A sociological analysis of scientists' discourse. Cambridge: Cambridge University Press.

Goffman, E. 1955. On face-work: An analysis of ritual elements in social interaction. Psychiatry: Interpersonal and Biological Processes 18 (3): 213-231. 1959. The presentation of self in everyday life. London: Penguin.

Goodell, R. 1975. The visible scientists. Boston: Little, Brown \& Company.

Greiffenhagen, C., and W. Sharrock. 2011. Does mathematics look certain in the front, but fallible in the back? Social Studies of Science 41 (6): 839-866.

Hilgartner, S. 2000. Science on stage: Expert advice as public drama. Stanford: Stanford University Press.

2004. The credibility of science on stage. Social Studies of Science 34 (3): 443-452.

Horst, M. 2013. A field of expertise, the organization, or science itself? Scientists' perception of representing research in public communication. Science Communication 35 (6): 758-779.

Horst, M., S.R. Davies, and A. Irwin. 2016. Reframing science communication. In The handbook of science and technology studies, ed. U. Felt, R. Fouché, C.A. Miller, et al., 4th ed., 881-907. Cambridge: MIT Press.

Irwin, A. 2006. The politics of talk: Coming to terms with the 'new' scientific governance. Social Studies of Science 36 (2): 299-320. 
Jacobi, D., and B. Schiele. 1989. Scientific imagery and popularized imagery: Differences and similarities in the photographic portraits of scientists. Social Studies of Science 19 (4): 731-753.

Jurdant, B. 1993. Popularization of science as the autobiography of science. Public Understanding of Science 2 (4): 365-373.

Lam, A. 2010. From 'Ivory Tower Traditionalists' to 'Entrepreneurial Scientists'? Academic Scientists in Fuzzy University—Industry Boundaries. Social Studies of Science 40 (2): 307-340.

Latour, B. 1987. Science in action: How to follow scientists and engineers through society. Cambridge Mass: Harvard University Press.

Lee, H. 2006. Privacy, publicity, and accountability of self-presentation in an on-line discussion group. Sociological Inquiry 76 (1): 1-22.

Myers, G. 2003. Risk and face: A review of the six studies. Health, Risk \& Society 5 (2): 215-220.

. 2007. Commonplaces in risk talk: Face threats and forms of interaction. Journal of Risk Research 10 (3): 285-305.

Palmer, S.E., and R.A. Schibeci. 2014. What conceptions of science communication are espoused by science research funding bodies? Public Understanding of Science 23 (5): 511-527.

Ponterotto, J.G. 2006. Brief note on the origins, evolution, and meaning of the qualitative research concept thick description. The Qualitative Report 11 (3): 538-549.

Shapin, S., and B. Barnes. 1977. Science, Nature and Control: Interpreting Mechanics' Institutes. Social Studies of Science 7 (1): 31-74.

Shapin, S. 1990. Science and the public. In Companion to the history of modern science, ed. R.C. Olby, G.N. Cantor, J.R.R. Christie, et al., 990-1007. London: Routledge. . 1994. A social history of truth: Civility and science in 17th century England. Chicago: The University of Chicago Press.

- 2010. Never pure: Historical studies of science as if it was produced by people with bodies, situated in time, space, culture, and society, and struggling for credibility and authority. Baltimore: JHU Press.

Topham, J. 2009. Rethinking the history of science popularization/popular science. In Popularizing science and technology in the European periphery, 1800-2000, ed. F. Papanelopoulou, A. Nieto-Galan, and E. Perdiguero, 1-10. Aldershot: Ashgate.

Weingart, P., C. Muhl, and P. Pansegrau. 2003. Of power maniacs and unethical geniuses: Science and scientists in fiction film. Public Understanding of Science 12 (3): 279-287.

Open Access This chapter is licensed under the terms of the Creative Commons Attribution 4.0 International License (http://creativecommons.org/licenses/by/4.0/), which permits use, sharing, adaptation, distribution and reproduction in any medium or format, as long as you give appropriate credit to the original author(s) and the source, provide a link to the Creative Commons license and indicate if changes were made.

The images or other third party material in this chapter are included in the chapter's Creative Commons license, unless indicated otherwise in a credit line to the material. If material is not included in the chapter's Creative Commons license and your intended use is not permitted by statutory regulation or exceeds the permitted use, you will need to obtain permission directly from the copyright holder.

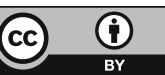

